\title{
Erratum to: Writing to the Common Core: teachers' responses to changes in standards and assessments for writing in elementary schools
}

\section{Kristen Campbell Wilcox ${ }^{1} \cdot$ Jill V. Jeffery ${ }^{2}$.} Andrea Gardner-Bixler ${ }^{1}$

\section{Erratum to: Read Writ \\ DOI 10.1007/s11145-015-9588-6}

The last name of the second author has been incorrectly published in the original article. The correct name is provided in this erratum.

The online version of the original article can be found under doi:10.1007/s11145-015-9588-6.

Kristen Campbell Wilcox

Kwilcox1@albany.edu

1 Department of Educational Theory and Practice, School of Education, University at Albany, ED 115A, 1400 Washington Ave, Albany, NY 12222, USA

2 CUNY-Brooklyn, Brooklyn, NY, USA 